\title{
The Taiwan system of innovation in the tool machine industry: a case study
}

\author{
Ching-Chiang Yeh*, Pao-Long Chang \\ Institute of Business and Management, National Chiao Tung University, \\ 4F, 114 Section 1, Chung-Hsiao West Road, Taipei, Taiwan
}

\begin{abstract}
Recent evidence suggests that the Taiwan's machine tool industry as a whole is prominent in the world, ranking sixth in output and fifth in exports. This paper explores the current status and features of Taiwan's national systems of innovation (NSI) for its machine tool industry. It is suggested that five major elements of the NSI explain the extensive diffusion of new technologies in the industry, namely: industry clusters, educational system, bridging institutions, government policy, and global business environment. Further, the structural and institutional problems of the innovation system are identified. Future directions of technology development are also discussed.
\end{abstract}

(C) 2003 Elsevier B.V. All rights reserved.

Keywords: National systems of innovation; Machine tool industry; Industry cluster; Government policy

\section{Introduction}

In recent years, technological innovation has been increasingly recognized as the engine for economic growth. Technological innovation is viewed as "the transformation of an idea into a new or improved saleable product or operational process in industry or commerce, etc." (Roy and Wield, 1985). An important aim of the theory of national systems of innovation (NSI) (Lundvall, 1992) is to assist in explaining the direction of technological development at the national level, by means of a combination of economic structure and national institutional setup. The concept of the NSI was introduced by Freeman (1987) and has since been widely disseminated by Edquist (1997); Lundvall (1992); Nelson and Rosenberg (1993), and Niosi et al. (1993).

Freeman (1987) introduced the term NSI in his study of Japan. He defined the NSI as "the network of institutions of private and public sector, whose activities and interactions

\footnotetext{
* Corresponding author. Tel.: +886-2-29472213; fax: +886-2-23610656.

E-mail address: u8531806@cc.nctu.edu.tw (C.-C. Yeh).
} 
initiate, import, modify, and diffuse new technologies." Lundvall (1992) defined a NSI in terms of "elements and relationships which interact in the production, diffusion, and use of new and economically useful, knowledge ..., either located within or rooted inside the borders of a nation state." Nelson and Rosenberg (1993) conceptualized the NSI in terms of a set of institutions whose interaction result in firms designing and developing products and process that are new to them. All these studies tried to understand innovative capabilities in relation to various institutions that are present in the countries under study.

The machine tool industry is a basic manufacturing sector because it produces the inputs for its own production and for all other manufacturing processes. With fast development of innovative technology and intense competition in the global machine tool industry, the main machine tool plants in the world are now concentrated in Japan, the United States, and Europe. Of the top ten machine tools plants, six are Japanese firms, two are American, one is German and one is Italian. Moreover, recent evidence suggests that the Taiwan's machine tool industry as a whole is prominent in the world, ranking sixth in output and fifth in exports. The development of the machine tool industry in Taiwan has already spanned several decades. The industry has been playing the role of crucial components supplier for the Taiwan's manufacturers, both in domestic manufacturing and in export trade.

The object of this article is two-fold. The first is to explore the salient features of the Taiwan innovation system with respect to the machine tool industry. Second, we identify problems in the innovation system and recommend solutions for those problems.

This paper is organized as follows. Section 2 puts into perspective the machine tool industry's production system. Section 3 summarizes the results of the innovation system for the Taiwan's machine tool industry and evaluates innovation performance. Section 4 discusses the problems in the industry's innovation system along with some proposed solutions.

\section{Production system for the Taiwan's machine tool industry}

Machine tools are divided into cutting tools and forming tools. Japan, the US, and Europe are focused on cutting machine tools, while Taiwan has an output ratio of 66:34 between cutting machine tools and forming machine tools ((Mechanical Industry Research Laboratories (MIRL, 1998))). Among cutting machine tools, Numerically controlled (NC) lathes command the highest price and machining centers the second highest. Together these divisions account for one-third of total machine tools output and the major products of the industry.

Table 1 shows that the Taiwan's machine tool industry is $76 \%$ made up of cutting machine tool plants and is concentrated in the Taichung area, with a degree of concentration of up to $55 \%$, and with cutting machine tools even reaching $64.5 \%$ concentration. Eighty-eight percent of Taiwan machine tool plants are small and medium enterprises with capitalization under NT\$ 60 million and fewer than 100 employees (MIRL, 1998). In sum, the Taiwan's machine tool industry is mainly made up of small and medium plants producing cutting machine tools located in Taichung area.

In output as well as location the Taiwan's machine tool industry is highly concentrated, with the output of the top five firms totaling $19 \%$ of the industry output, that of the top 
Table 1

Area distribution of Taiwan's machine tool plants

\begin{tabular}{|c|c|c|c|c|c|c|}
\hline \multirow[t]{2}{*}{ Area } & \multicolumn{2}{|c|}{ Forming machine tools } & \multicolumn{2}{|c|}{ Cutting machine tools } & \multicolumn{2}{|l|}{ Total } \\
\hline & $\begin{array}{l}\text { Number } \\
\text { of plants }\end{array}$ & Percentage & $\begin{array}{l}\text { Number } \\
\text { of plants }\end{array}$ & Percentage & $\begin{array}{l}\text { Number } \\
\text { of plants }\end{array}$ & Percentage \\
\hline Yilan, Hualien, and Taitong & 1 & 0.92 & 0 & 0 & 1 & 0.21 \\
\hline Taipei city and county & 36 & 33.03 & 57 & 15.92 & 93 & 19.91 \\
\hline Taoyuan, Hsinchu, and Miaoli & 13 & 11.73 & 30 & 8.38 & 43 & 9.21 \\
\hline Taichung city and county & 28 & 25.69 & 231 & 64.53 & 259 & 55.46 \\
\hline Changhua and Nantou & 12 & 11.01 & 10 & 2.79 & 22 & 4.71 \\
\hline Yunlin and Chiayi & 7 & 6.42 & 7 & 1.96 & 14 & 3.00 \\
\hline Tainan city and county & 9 & 8.26 & 12 & 3.35 & 21 & 4.50 \\
\hline Kaohsiung and Pingtong & 3 & 2.75 & 11 & 3.07 & 14 & 3.00 \\
\hline Total & 109 & 100.00 & 358 & 100.00 & 467 & 100.00 \\
\hline
\end{tabular}

Source: MIRL, 1998.

10 firms totaling 29\%, and that of the top 20 totaling 41\% (MIRL, 1997b). The degree of concentration differs for types of machines. For NC lathes, the top six plants contribute $74 \%$ of total output. For machining centers, the top seven plants contribute $82 \%$ of the total output of vertical models.

Victor Taichung Machinery Works Co. is the biggest machine tool plant in Taiwan, but compared with global revenue leaders it is still small. The largest plant in terms of revenue in 1996 was in Japan; that plant had about 11 times the revenue of Victor Taichung. Even the tenth ranked plant, in Switzerland, had revenues about six times those of Victor Taichung, implying that Taiwan's machine tool plants need to further augment their business scale.

Sixty percent of the Taiwan's machine tool industry is mainly focused on the overseas market, in Mainland China, Hong Kong, the United States, Thailand, and Malaysia. Cutting machine tools are the major products. Due to Taiwan's Mainland China investment policy tide, which started in 1992, machine tools exported to the Mainland via Hong Kong have reached $28 \%$ of Taiwan's machine tool exports, with China now the largest export country for Taiwan's machine tools.

A complete production system has been formed in the Taiwan's machine tools industry except for key components. Among the key components not produced indigenously are computer numerical control (CNC) controllers, spindle motors, serve motors and serve driving systems, and motor built-in spindles (MIRL, 1998); these are mostly imported from Japan and have been decreasing due to the appreciation of the Japanese yen. Lately, imports from the United States have been growing steadily, and the United States is the second largest supplier for Taiwan's machine tools components. Germany, Switzerland, and Italy account for less than $10 \%$ of imports. After Taiwan's plants started relocating to Mainland China, China also became a major supplier, starting in 1994.

Besides lack of technological breakthroughs, inadequate market scale is a block for Taiwan. Furthermore, most domestic plants do not have adequate financial resources and manpower to set-up integrated maintenance and service systems. Currently the Japan-produced CNC controller occupies over $98 \%$ of the market. Its purchase price is extremely high, preventing Taiwan's machine tool plants from further reducing their costs. 


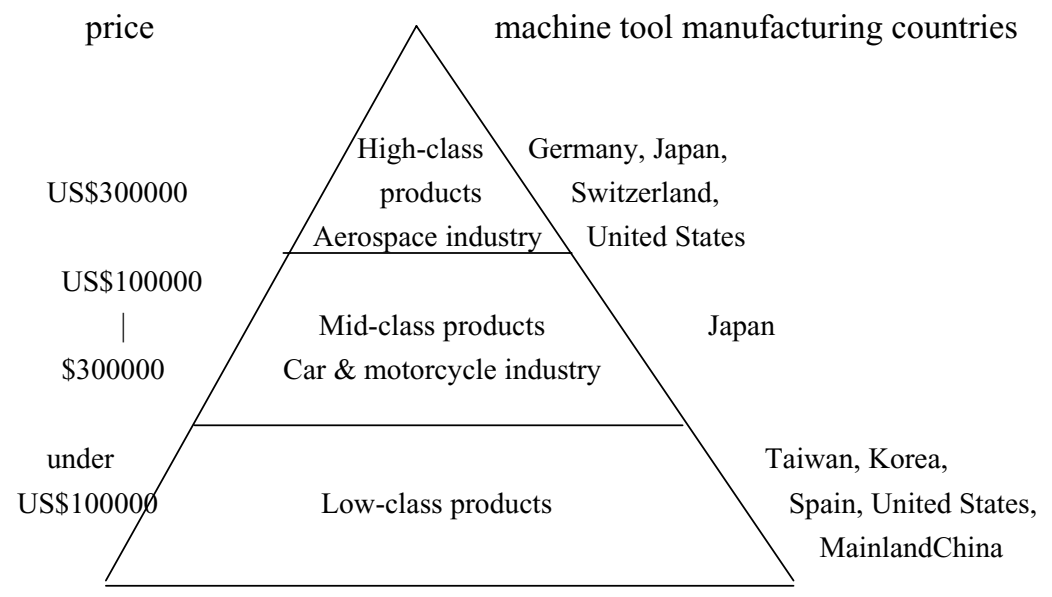

Fig. 1. Global market positioning of Taiwan's machine tools. Source: MIRL, 1997a.

Despite the fact that Taiwan's machine tools output ranks sixth in the world, Taiwan still has an import dependence of 50-60\% for machine tools, $80 \%$ of which are cutting machine tools. Beside the grinder, NC lathes are Taiwan's major imported machine tool. Most are imported from Japan, followed by the United States. The imported machines are primarily high priced, high value-added products. Most of the machine tools are for car plants and semiconductor fabrication. The reason for importing such machine tools are their superior quality.

Japanese Nomura General Research Department argues that machine tools can be divided into three classes based on their quality in the world as shown in Fig. 1. Production of high-quality machine tools depends heavily on technological levels maintained by the German, Swiss, Japanese, and the United States. These machine tools are mainly used in high-precision industries such as aerospace. Meanwhile, $75 \%$ of the machine tools market is concentrated in the mid-class machine tools category. These tools are used in the automobile and motorcycle industries, where supplied is dominated by Japan. Low-end machine tools for general purposes are mainly produced by Taiwan, Korea, US emerging plants, and Mainland China, but their market share is only $20 \%$ of the total machine tools market (MIRL, 1997b).

\section{National systems of innovation for Taiwan's machine tool industry}

In a free market economy, a nation's innovation system is an integral part of its economic system. It is understood as a set of different institutions such as business firms, R\&D and training centers, and government agencies which cooperate and even in certain circumstances compete within organized markets (Lundvall, 1988). Institutions link and interact in order to benefit from each other's knowledge and competencies (Lundvall, 1992; Galli and Teubal, 1997). Each institution provides the NSI with specific kinds of knowledge, all of which are necessary for successful innovation performance. 


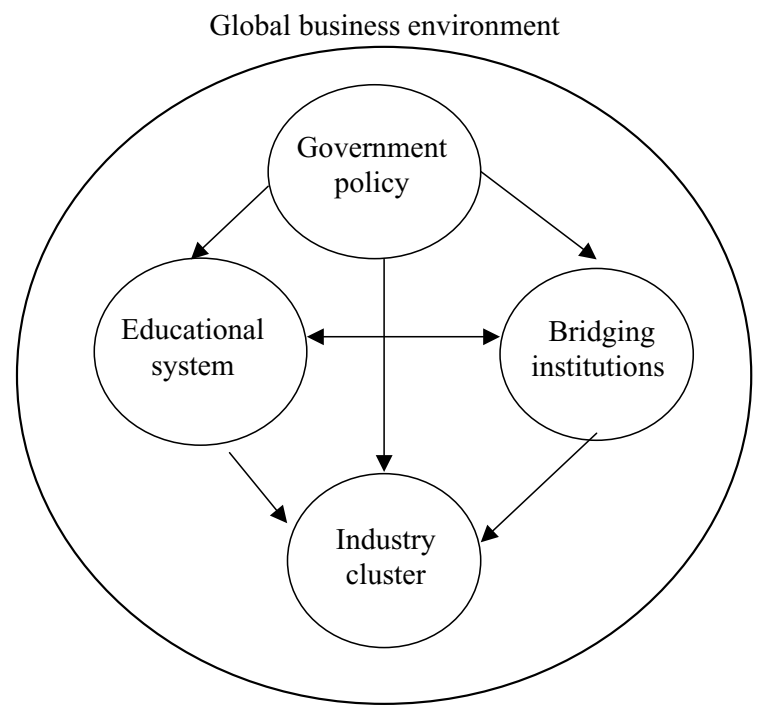

Fig. 2. Main elements of NSI for Taiwan's machine tool industry.

A national style of innovation system may have important differences at the sectorial level. Sector characteristics, in terms of positive externalities, cumulation, and synergy, determine the peculiar performance of the single firms (Pavitt, 1984). Therefore, the sectoral specific features are important for the institutional set-up, and for interactive learning between innovating institutions. In this article we propose that Taiwan's machine tool industry is a special configuration of Taiwan's NSI.

In order to provide a context for discussion, consider Fig. 2, a representation of the NSI for the Taiwan's machine tool industry. The main elements of the innovation system are (1) the industry cluster formed by the machine tools industry based on factory satellite network system at Taichung area; (2) the educational system; (3) bridging institutions formed by government supported research institutes; (4) government policy; and (5) global business environments. Each element will be explained below.

\subsection{The industry cluster}

An essential aspect underlying the industry cluster is the development of close co-operative relationships. As machining centers and NC lathes are the major machine tools in Taiwan, this section describes the factory satellite network system by taking as examples NC lathes produced by Victor Taichung and machining centers produced by Yochia Enterprise. The major actors of the factory satellite network system in the industry cluster at Taichung area are as follows:

\subsubsection{Central plant}

It becomes a designer and assembler rather a manufacturer. It is responsible for the $\mathrm{R} \& \mathrm{D}$, design and final assembling and testing of machine tools. It determines the important 
performance criteria in-house or by outsourcing decisions; technological capability, delivery, and precision are required. Except for items to be manufactured in-house, all the processes, parts, and components are supplied by satellite plants. Great care has to be exercised in the satellite plants' selection.

\subsubsection{Satellite plants}

They are all geographically close to central plants. Satellite plants can be classified by capability as follows:

(1) Plants that provide general components: They are like hardware stores providing varieties of high level, standardized small components such as gears and other hardware parts. The central plant provides the design specification for the satellite plants to mass production and standardize at the level of economy of scale.

(2) Plants that provide process technologies: Process technologies such as foundry, respray, and heat treatment can be supplied by satellite plans specialized in the process. Certain process technologies such as Yochai's respray and scrapping are outsourcing for satellite plants to work in-house. These satellite plants permit extensive customization and product differentiation.

(3) Plants that provide specializing accessories: For example, $85 \%$ of the iron scrap conveyers was provided by the specialized satellite plants of Homge. Golden-Sun is the sole manufacturer of rotating beds. Six-star is a specialized cutting tool turret plant. These specialized satellite plants are capable of flexibility and rapid response, allowing the central plant to achieve economy of scale by specialized production.

(4) Firms that provide key components. These specialize in specified key components such as CNC controllers, main spindle bearings, and ball screw. The central plant must take these standard specifications into consideration in the R\&D stage. Although some satellite plants are able to provide certain key components, most of them rely on agents who import due to concern for precision and quality.

Within the cluster, reflecting long-term commitment, central plants and satellite plants may develop complex relations to manage the flow of goods and services across the factory satellite network system. Four types of interactive relations are evident within factory satellite network system:

\subsubsection{Personnel interaction}

Among the satellite plants of Victor Taichung, more than 10 satellite plants were founded by ex-employees of the Victor Taichung. Yochia Enterprise provides an opportunity for experienced employees as independent subcontractors in-house; they have full understanding of the central plant's requirement of manufacturing and quality capability. In case of problems, prompt notification and immediate solutions can be obtained through cooperation.

\subsubsection{Technological interaction}

Central plants recognize that improved satellite plant manufacturing capability is critical to achieving their own performance improvements. The central plant holds regular meetings with satellite plants to share understanding of this policy. Technological experience is also 
shared. Together the parties map out satellite and central plant development in the future, including adjustments of central plant capability.

\subsubsection{Informational interaction}

Victor Taichung is linked by computers network with 15 satellite plants. Through this computer network, satellite plants are able to access the central plant's future demands for material and its current supply status, as well as focus on their own production and material planning. This greatly reduces environmental uncertainty and the satellite plants are able to engage in $R \& D$ for process technology.

\subsubsection{Financial interaction}

As most satellite plants are small businesses and awkward at financial arrangement, the central plant provides appropriate financial incentives to satellite plants. Victor Taichung offers different levels of financial incentives by formal evaluation of satellite plants performance. For A-class firms, payment is in cash. For B-class firms, payment is by favored 1-month check.

This factory satellite network system structure supports a high level of dependency in the industry cluster, enabling greater technological diffusion, facilitating tighter communication and co-operation, and supporting the development of machine tools. Within the factory satellite network system, each actor focuses on mutual assistance, intensive and regular sharing of technological information, trust and cooperation without competition. Factory satellite network system relationships are said to benefit both central plants and satellite plants in improved products, quality, lead-time, and cost reduction.

The manufacturing costs of Taiwan's machine tool plants are shown in Table 2 (MIRL, 1998). $28.3 \%$ is for imported components that either can not be produced domestically or that replace domestic products that can not meet the plant's quality requirements. When the domestically supplied parts are included, direct material takes up $46.1 \%$ of the machine tool operating cost. Many machine tool plants outsourcing their process to satellite plants, creating outsourcing expenses of $15.9 \%$. Taiwan's machine tools are unusual in that about $62 \%$ of total operating cost consist of components and process from satellite plants. It reflects that the major competitive advantage of the Taiwan's machine tool industry lies in flexibility, delivery, and low price through the industry cluster.

Table 2

Cost structure for Taiwan's machine tool plants

\begin{tabular}{|c|c|c|}
\hline Classification of costs & & Percentage \\
\hline \multirow[t]{5}{*}{ Manufacturing cost } & Direct materials & 28.3 \\
\hline & Domestic & 17.8 \\
\hline & Direct labor & 11.3 \\
\hline & Factory overhead & 11.8 \\
\hline & Outsourcing expenses (satellite plants) & 15.9 \\
\hline Commercial expenses & & 14.9 \\
\hline Total operating cost & & 100 \\
\hline
\end{tabular}

Source: MIRL, 1998. 


\subsection{Educational system}

Most Taiwan's machine tool employees are high-school graduates, followed by college graduates (MIRL, 1993). The employees' average length of service is 6.6 years and their average age is 31.1 , both relatively low. The quality of human resources for the Taiwan machine tool industry has yet to be enhanced.

The educational system, in particular the universities and institutes of technology, play an important role in the generation and diffusion of knowledge. Taiwan's academic sector has contributed merely to a limited extent in the technological development of the machine tool industry. This technological deficiency is particularly attributable to the theory-oriented nature of Taiwan's educational system. Most employees hired right out of school can not fully master practically applicable skills in machine tool areas. So, on-the-job training provides most of the specialized skills that are used in work.

In recent years, the Ministry of Education (MOE) has regularly held activities for education providers to participate in practical studies with industry. The purpose is to let schools understand the state of industrial technologies and the human resources required by the industry in response to industry demand. In addition, the MOE has been encouraging professors to co-develop required technologies with plants. An example is Tonghai University's joint projects with machine tool plants for technology transfer and guidance.

With higher living standards in society, better working conditions and environments are now demanded, so the difficulties in recruiting employees for machine tool plants have gradually become serious. Consequently, Taiwan's machine tool plants proactively engage in co-operative programs with local schools, hoping to attract graduated co-op students into jobs related to the production of machine tools. For the machine tool industry, an important topic is how to further develop and retain employees.

\subsection{Bridging institutions}

Taiwan's academic infrastructure has contributed only to a limited extent in the R\&D of machine tools. Being composed of small and medium-size firms, the major R\&D activities for the Taiwan's machine tool industry must rely on government-sponsored bridging institutions. Taiwan's government has entrusted significant human and financial resources to the promotion of technology for bridging institutions. Therefore, government-sponsored bridging institutions are critical to technological development and diffusion in Taiwan's machine tool industry.

Some of the more important bridging institutions are the Mechanical Industry Research Laboratories (MIRL) of the Industrial Technology Research Institute (ITRI), the Metal Industries Research \& Development Center (MIRDC), and the Precision Machinery Research $\&$ Development Center (PMC). In general, MIRL is more oriented toward technological development in machine tools, while the MIRDC is heavily involved in related process technology for forming machine tools, besides being engaged in the guidance and evaluation of ISO 9000 and CE certification. As for the PMC, its main aim is to assist machine tools software, testing, and electronic control by guiding plants in obtaining ISO 9000 and CE certificates.

Among bridging institutions, the MIRL is relatively sophisticated in its own R\&D capability and its well-trained workforce. Its specialized personnel have made a significant 
contribution to the machine tool industry in the development of state-of-the-art technologies. It was recognized that no local plants by their own efforts alone are likely to produce world-class products. Bridging institutions have created a resource for engineers by bringing the various firms together to engage in developing technology to boost domestic industrial development. Some of their recent achievements are listed below.

\subsubsection{Technological development}

Ministry of Economic Affairs' (MOEA) Scientific \& Technological Development Project (STDP) was entrusted to work on key projects with core technologies in automation, power machinery, and precision machinery. Programs related to the machine tool industry are as following: precision machinery program, computer integrated automation program, machinery industry's key components program, and electric machinery program. In the precision machinery program; they have developed key module technology and set-up common technology such as the high-speed main spindle, the high-speed feeding system, the work exchange system and screw components technology. The computer integrated automation program has integrated domestically designed/produced CNC and machining centers with flexible manufacturing systems.

The machinery industry's key components program has yielded new technologies such as: a precision transmission for decelerators, a spinning workstation as a loader, a built-in spindle for high-speed machine tools to avoid transmission-derived problems using traditional spindles, and a linear guideway in response to automation requirements and cost considerations. In the electric machinery program; it has developed PC-based industrial controller system technology, and obtained CE certification. These technologies have been successfully transferred to major domestic machine tools plants and component plants.

\subsubsection{Industrial services}

NT\$ 1.14 billion came from execution of contracted services provided in 1997, with 1153 firms being served. It was estimated that NT\$ 3.6 billion can be obtained by plants as a direct benefit of cost reductions or sales increases. In combination with the execution of the technological development program, industrial services can effectively help to advance Taiwan's machine tool industry in global competition.

\subsubsection{Manpower training}

The capability of human resources was further upgraded through the Industrial Development Bureau (IDB) commissioned training courses in automation and machinery designing, in association with MOE-commissioned seminars for vocational school teachers. As a result of the technological development program's presentations and conferences (average of 140 sessions per year), 4500 high-tech personnel have been trained and diffused into industry and vocational schools.

\subsubsection{Others}

Awea Mechantronic Co. and Shu-long Precision Co. were founded based on manpower diffused from the MIRL and technology transfers to industry. Some spin-off companies such as Mengli Automation and Ruichi Precision Machinery were also founded. MIRL also helped machine tool plants in transformation to get into the semiconductor equipment 
industry. Victor Taichung's proton-flow controller and Yang Iron's wafer cutter are the examples. These have significant meaning for the industry's future development. Recently, $\mathrm{CNC}$ machines have enjoyed significant increase in sales, indicating that technological level of Taiwan's machine tools has advanced and higher-level machines are ready to compete in the market.

It is obvious that the government-sponsored bridging institutions have played important roles of encouraging technological innovation in the Taiwan's machine tool industry.

\subsection{Government policy}

The Taiwan government plays a leading and direct role in the institutional set-up of the machine tool industry system of innovation. In order to encourage the domestic industrial sector to invest in R\&D, Taiwan government has introduced incentive policies offering tax reductions, loans, and grants for the development of specific technologies (Chang and Hsu, 1998). Beyond these policies, the government promotes R\&D in the machine tools industry through the following.

\subsubsection{The National Science Council's (NSC) Industry-University Cooperation Program (IUCP)}

This is an academic sector-based R\&D effort for fundamental technology. The program allows academics to understand the technology required for machine tools and assists in establishing good interactive relationships between the academic sector and the machine tools industry.

\subsubsection{MOEA technology division's STDP}

This project leads bridging institutions to focus on R\&D of application technology, with concrete results transferred to plants. Through STDP, several center plants and satellite plants have developed their own R\&D capability, which in turn boosts the R\&D capability of the industry cluster. Since 1997, STDP has been lead by private plants, such as Yochia Enterprise' research in the "composite surface processing technology."

\subsubsection{MOEA IDB's New Leading Product Development Program (NLPDP)}

Plants encouraged to participate the program focus on the R\&D of new products and build up R\&D teams to promote industrial R\&D capability and to enhance industrial technological levels. The program appeals to low-cost technology, aiming to synchronize functions with other parts of the world. There is a lag in machine tool precision and cutting capability.

To further upgrade the capability of human resources, the MOE has been assigned, under the project of industrial automation, to restructure courses related to automation, to train education providers and to improve in teaching materials. High-level R\&D personnel can be trained through NSC's IUCP. The Employment and Vocational Training Administration of the Council of Labor Affairs promotes the training and certification of automation technicians. The government has also organized conferences on related technologies every year by combining institutions of higher learning with research organizations, and is co-operating to meet the requirements of industrial development. Over 10,000 in-service 
personnel attended these training sessions each year. However, it is still inadequate in the training of systems and integration personnel that require longer development time.

As for financing, currently only three machine tool plants, Victor Taichung, Lisan Industrial, and Yang Iron, issue securities to the public. Yochia Enterprise, Leadwell Manufacturer, and a specialized component plant Shangyin Co. have been planning on taking to over-the-counter trading for a major source of development financing.

\subsection{Global business environment}

Current trends of technological development in the global machine tools market tend to be with the features of low prices, high speed, high precision, open controllers, composition of the industry in terms of low to high-class products, parts standardization and modularization, environmental protection, and networked systems (MIRL, 1997b). As the Taiwan's machine tool industry is export-oriented, the trend for technological development in the global machine tools market has a significant impact on the direction of technological development for Taiwan's machine tools.

The composition of industrialized countries' machine tool industries in terms of the low, medium, and high-class products that they make is about 25:65:10, respectively, while the composition for newly developing countries is 80:19:1 (PMC and MIRL, 1996). In Asia, Taiwan's main competitors are Japan, Korea, and Mainland China. Taiwan's machine tools, second only to Japan's in terms of quality and sales in Asia, are offered at much lower prices than Japan's. Consequently, they are attractive to the Southeast Asian market. The current car parts market structure will change after local car parts plants, using machine tools other than those produced by Japan, emerge. Besides, the vigorously growing semiconductor industry, the high-potential aerospace industry, and the health care industry are all machine tool markets for high-precision and processing technology. Consequently, the Taiwan machine tool industry will likely develop in the direction of mid-class machine tools.

Analyzed by machine tool products, the currently industrialized countries have over $50 \%$ of NC-based cutting machine tools (PMC and MIRL, 1996). It is especially clear that NC machines have advantages in situations where technical employees are in shortage, where land costs and labor costs are constantly rising, and where product models change rapidly. $\mathrm{NC}$ machine tools have been gaining in productivity, function, price, and applications. The ratio of NC-based machine tools to other machine tools has been used as a benchmark to rate machine tool industries and manufacturing technology.

\section{Problems of NSI for Taiwan's machine tool industry}

Although the NSI for Taiwan's machine tool industry has significantly contributed to the development of the industry, the system faces structural and institutional problems. The structural problem refers to the product composition of production and exports. The institutional problem refers to the institutional framework of the economy, reflecting changes in how the relationships between the elements of NSI for Taiwan's machine tool industry.

In the following discussion, we shall point to three fundamental structural problems along with four institutional problems facing the NSI for Taiwan's machine tool industry. 
The structural problems include:

1. Most plants are small and medium enterprises with limited sales and R\&D capability. Due to weak fundamental technologies, resulting in weak peripheral and system technological capability for machine tools. It is difficult for Taiwan to make key components indigenously, resulting in heavy imports from Japan and causing high manufacturing cost that block competitive advantage enhancement. Therefore, government should help the plants to build up the key components industry to enhance competitiveness for the industry cluster. Plants also should make the best utilization of government R\&D resources and varieties of financial preferential measures to upgrade their technology capability.

2. Due to low-class machine tools, with their high homogeneity and low values added, plants tend to compete by cutting prices. Korea, Mainland China, and Southeast Asia among newly emerging countries are aggressively taking advantage of their low-cost labor to gain market share for low-class machines, while European countries, the United States, and Japan are aggressively entering the mid-class market. Taiwan's machine tool industry is being squeezed in the middle. To respond to this, Taiwan's machine tool industry should further set-up strategic alliance system to avoid cut-price competition and by standardizing and co-developing components of the assembly-oriented Taiwan's machine tools, and achieving economies of scale to rapidly deliver low-cost machine tools.

3. During the past 5 years, as Taiwan's machine tools have become concentrated in the export market, risks have thus become much higher. As a result, the machine tool plants should work hard to collect global information and diversify the export market.

In addition to the structural issues outlined above, there are four fundamental institutional problems:

1. One fundamental characteristic of the innovation system for Taiwan's machine tool industry is the absence of coordinating agency. Currently the R\&D of machine tools are sponsored by NSC's IACP, the MOEA Technology Division's STDP and MOEA IDB's NLPDP. Units engaged in R\&D include universities, bridging institutions, and machine tool plants. Government must integrate among R\&D programs and engaging units to achieve maximum effects.

2. Due to the problem of rising land costs, resulting with difficulty in establishing new plants, so government should improve operation environments to setting up a machine tools special zone in Taichung area to build up a key components industry.

3. Academic institutions rarely hire people who have practical experiences in industry that the technological capability for R\&D and manufacturing of machine tools can continue to accumulate. One possibility is to strengthen the academic sector joint cooperation with the machine tool plants, to make academic knowledge useful for the machine tool industry, and to make the educational providers realize the problems and requirements of the machine tool industry.

4. Bridging institutions rely heavily on government support for a long time. As the shortage of financial resources by government, $R \& D$ activities will be affected resulting in weak technological capability. The technology in the bridging institutions comparison with states of the art has lagged, so bridging institutions should aggressively encourage plants to undertake joint or strategic alliances in $R \& D$ activities to share the limited $R \& D$ 
resources and make sure the technology could be commercialized. Bridging institutions should also aggressively participate in international R\&D organizations to establish co-operative development, introduce advanced technology from abroad and recruiting foreign experts to work in Taiwan to accelerate the technology development.

\section{Concluding remarks}

The Taiwan's machine tool industry is mainly composed of small and medium enterprises located in the Taichung area and engaged in manufacturing cutting machine tools. The industry is highly concentrated and export-oriented, with low-class, general-purpose machines. Key components are imported, especially from Japan.

The following features can be used to explain the current success of the Taiwan's NSI in the machine tool industry:

1. The competitive advantages achieved though flexibility, delivery, and price by the userproducer interaction of the factory satellite network system in the industry cluster in the Taichung area.

2. The success of the diffusion of technology from bridging institutions to industry has been an important factor.

3. The key roles played by the government in the innovation system.

In response to global business environment, the direction of technological development for Taiwan's machine tool should focus on the following.

\subsection{Mid-class machine tools}

Because Taiwan's machine tools lag behind those of advanced countries in precision and reliability, and the technological gap with Korea and Mainland China is closing, focus should be placed on mid-class machine tools.

\subsection{NC-based simple machines}

Traditional machine tools command $40 \%$ of the global market share. Because of lack of automation capability, they provide less competitiveness in an environment of labor shortage and hiked labor costs. On the other hand, NC machine tools are expensive. To users with limited financial resources, traditional machine tools combined with PC and controllers can be function as simple NC machine tools and meet user demands yet at an acceptable price. Taiwan can take advantage of its strong PC technology to create a new industry for simple machine tools.

\subsection{Automated production unit}

Automated production has become an inevitable trend due to changes in the manufacturing environment. Single-machine automation does not meet users' requirements. For convenience, users ask machine tool plants to provide flexible manufacturing cells (FMC) 
or system integration technology for production. On the other hand, the single machine is fixed in price while integrated manufacturing systems will increase the values that are added. Therefore, the automated production unit is a new territory Taiwan machine tool plants should get into.

\section{References}

Chang, P.L., Hsu, C.W., 1998. A quality management model for research institutes responsible for government-supported R\&D projects. International Journal of Technology Management 16 (4-6), 393-404.

Edquist, C., 1997. System of innovation approaches - their emergence and characteristics. In: Edquist, C. (Ed.), Systems of Innovation: Technologies, Institutions and Organizations. Pinter, London.

Freeman, C., 1987. Technology and Economic Performance: Lessons from Japan. Pinter, London.

Galli, R., Teubal, M., 1997. Paradigmatic shifts in national innovation systems. In: Edquist, C. (Ed.), Systems of Innovation: Technologies, Institutions and Organizations. Pinter, London.

Lundvall, B.A., 1988. Innovation as an interactive process: from user-producer interaction to the national systems of innovations. In: Dosi, G., Freeman, C., Nelson, R., Silverberg, G., Soete, L. (Eds.), Technical Change and Economic Theory. Pinter, London, pp. 349-369.

Lundvall, B.A., 1992. National Systems of Innovations: Towards a Theory of Innovation and Interactive Learning. Frances Pinter, London.

MIRL, 1993. The Study for Components of Machine Tools. Research Report, Industrial Technology Research Institute, Taiwan (in Chinese).

MIRL, 1997a. Present Position and Trend Analysis of Mechanical Industry. Research Report, Industrial Technology Research Institute, Taiwan (in Chinese).

MIRL, 1997b. Taiwan Yearbook of Machine Tools. Research Report, Industrial Technology Research Institute, Taiwan (in Chinese).

MIRL, 1998. Taiwan Yearbook of Machine Tools. Research Report, Industrial Technology Research Institute, Taiwan (in Chinese).

Nelson, R., Rosenberg, N., 1993. Technical innovation and national system. In: Nelson, R. (Ed.), National Innovation Systems: a Comparative Analysis. Oxford University Press, Oxford.

Niosi, J., Bellon, B., Crow, M., Saviotti, P., 1993. National system of innovation: in search of a workable concept. Technology in Society 15 (2), 207-227.

Pavitt, K., 1984. Sectoral patterns of technical change: towards a taxonomy and a theory. Research Policy 13 , 343-373.

PMC and MIRL, 1996. The Strategy for Technological Development in Precision Machinery Industry. Research Report, Industrial Technology Research Institute, Taiwan (in Chinese).

Roy, R., Wield, D., 1985. Product Design and Technological Innovation: a Reader. Open University Press, Philadelphia. 